\title{
CRONOS Y LAS MOIRAS. LECTURAS DE LA TEMPORALIDAD EN LA MITOLOGÍA GRIEGA
}

\author{
OLAYA FERNÁNDEZ GUERRERO \\ Universidad de La Rioja
}

\begin{abstract}
RESUMEN: El artículo se basa en dos nociones de temporalidad, la circular y la lineal. Desde una perspectiva hermenéutica, se analiza la presencia de estas concepciones del tiempo en dos mitos griegos: Cronos (que representa el tiempo cósmico y natural) y las tres Moiras (que representan el tiempo finito y humano). También se analizan las figuras mitológicas de Mnemósine y de Dionisos, que hacen referencia a dos posibilidades diferentes de introducir modificaciones en el curso del tiempo.
\end{abstract}

PALABRAS CLAVE: Filosofía, Hermenéutica, Mitología griega, Tiempo.

\section{Chronos and the moires. Readings on temporality in greek mythology}

ABSTRACT: This article is based on two notions of temporality, the circular one and the linear one. From a hermeneutical approach, it traces the presence of both concepts of time in two Greek myths: Chronos (who represents the cosmic and natural time) and the Three Moires (who represent human, limited time). There is also an analysis of two other mythological characters, Mnemosyne and Dionysus, as they refer to two different possibilities of making changes in the time arrow.

KEY WORDS: Greek Mythology, Hermeneutics, Philosophy, Time.

Teseo no podía saber que del otro lado del laberinto estaba el otro laberinto, el del tiempo.

JoRge LuIS Borges

\section{INTRODUCCIÓN: MITO, LÓGOS Y TIEMPO}

El tiempo y la temporalidad humana han sido temas abordados por la filosofía desde sus orígenes griegos. Sin embargo, para entender las claves y fundamentos de esa reflexión tan arraigada en la metafísica occidental debemos retrotraernos hasta un discurso anterior a la filosofía, y no obstante muy vinculado a ella: el mito.

En Grecia se pone de manifiesto que «el mito es un lógos, una palabra en la que se hace presente la verdad» [Bermejo y Díez (2002), p. 57]. Los mitos son respuestas, explicaciones de las cuestiones que han inquietado al ser humano desde que tenemos constancia. La filosofía, por primera vez en el contexto griego y siempre a partir de entonces, se ha preguntado por esas mismas cuestiones y a la hora de buscar respuestas ha recurrido a diferentes elementos conceptuales y simbólicos, entre ellos el mito. De hecho, diferentes autores (Gadamer, Detienne, Jünger, Kirk o García Gual) han señalado la continuidad entre pensamiento mítico y pensamiento racional, contradiciendo así la idea de que el inicio de la filosofía occidental viene marcado por el paso del mito al lógos.

Los mitos siguen hoy formando parte de la filosofía, continúan interpelándonos porque hablan de nuestros modos de ser y percibir la realidad, y porque nos ofrecen un amplio catálogo de las pasiones y emociones que nos hacen ser humanos en cualquier tiempo y lugar. Los mitos «aún nos dicen algo profundo y 
enigmático sobre nosotros mismos» [García Gual (1997), p. 12] y tienen mucho más que enseñarnos porque su significado es inagotable, como intuyó Gadamer: «la tradición mítica entraña en sí misma un momento de apropiación pensante y se realiza por doquier volviendo a decir interpretativamente lo dicho en la leyenda» [(1997), p. 28]. Al apuntar hacia nuestro ser más intrínseco, y hacerlo además a través de relatos cuajados de símbolos, el mito inaugura un espacio interpretativo eminentemente dinámico que amplía los límites de la racionalidad y se abre a otro plano de sentido del que emergen los contenidos intuitivos y los elementos misteriosos, insólitos o contradictorios que nos constituyen ${ }^{1}$. Los mitos son topoi; en ellos se hacen presentes arquetipos, símbolos y referencias recurrentes que proporcionan claves muy valiosas - siempre y cuando sepamos descifrarlas- para llegar a comprender mejor lo humano ${ }^{2}$. Así, nuestra tarea interpretativa se basa en reconocer «el mythos, la trama, el hilo conductor, la historia de nuestra propia vida» [Downing (1998), p. 40] que palpita en los prolegómenos del pensamiento griego y, por ende, de toda la filosofía occidental.

Al igual que la filosofía, la mitología nos habla de problemas eternos [Kirk (2002), p. 75], y es en ese núcleo donde los mitos conectan con la metafísica, puesto que «el mito prepara la especulación al explorar el punto de ruptura entre lo ontológico y lo histórico» [Ricoeur (1982), p. 392]. El mito es un relato sobre el ser - por ello podemos afirmar con Ricoeur que tiene pretensiones ontológicas - que se presenta bajo la forma de una historia, de una narración que entraña cierta temporalidad, pero sin embargo y paradójicamente el mito está fuera del tiempo histórico; lo mítico se retrotrae hasta los orígenes, es siempre y por definición un relato fundacional. Los acontecimientos que los mitos relatan están fuera del tiempo en el sentido de que son previos al tiempo, y sirven por tanto para explicar el origen y la configuración de nuestra temporalidad. La mitología "no tiene fecha ni lugar de nacimiento, no comienza en ninguna parte» [Detienne (1985), p. 136] y de ahí se sigue que todo mito es acrónico y utópico (porque el lugar mítico siempre es imaginario; es un no-lugar). El mito es previo a la historicidad, pero precisamente por ese «estar fuera» de la historia puede dar cuenta de la misma, posibilitando e indicando un itinerario ontológico para conocer qué es el ser, para llegar a comprender nuestra estructura constitutiva temporal y los modos particulares en que «somos tiempo» - por decirlo con Heidegger - y en que nos experimentamos siendo en el tiempo y del tiempo. En todo mito resuena «la voz de un tiempo originario más sabio» [Gadamer

1 Por citar un ejemplo de esta posibilidad de apertura que el mito ofrece a la filosofía, recordemos cómo Platón logra, por medio de los mitos, iniciar ese proceso exegético de carácter abierto que ya está implícito en todo relato mitológico y que es potenciado al máximo bajo la forma del diálogo pues, como explica Emilio Lledó, «los mitos flotan sin amarras en el mar del lenguaje platónico. No hay nadie que pueda monopolizar su interpretación». Cfs. Lledó, E. «Introducción general a los Diálogos de Platón», en Platón (1997), Diálogos Vol. I, Madrid, Gredos, p. 117.

2 Como es sabido, la interpretación de los mitos como manifestaciones de arquetipos que forman parte del inconsciente colectivo ha sido desarrollada especialmente por el psicólogo alemán Carl Jung. Cfs. Jung, C. G. (2009), Arquetipos e inconsciente colectivo, Barcelona, Paidós. 
(1997), p. 16], una voz que apunta hacia un «antes» paradójicamente previo a toda temporalidad. Lo mítico siempre se retrotrae al tiempo primigenio, se ubica en el origen de los tiempos, se incardina - o mejor dicho, se disloca- en un no-lugar fuera del tiempo y ontológicamente anterior a éste.

En la mitología griega abundan las figuras que aluden a la temporalidad: las Horas; el dúo Deméter-Perséfone, que representa los ciclos de las estaciones; la Noche; Eos (la aurora), mensajera que anuncia el inicio de un nuevo día; Jano, el dios de dos caras que mira hacia el pasado y hacia el futuro... Dado que el análisis de todos esos mitos trascendería los límites de este trabajo, nos centramos en primer lugar en dos elementos mitológicos: Cronos - que encarna el tiempo de la naturaleza y de lo divino, de lo sagrado y replegado en sí mismo-, y el trío de las Moiras — que representan el tiempo lineal y finito, propio de los humanos- - La segunda parte del estudio se ocupa de dos figuras mitológicas que, cada una de un modo diferente, irrumpen en el tiempo lineal y lo transforman; se trata de Mnemósine (la memoria), y Dionisos (el éxtasis). Se plantea aquí una exégesis de estos mitos que pretende desentrañar la sabiduría que encierran acerca de nuestra temporalidad constitutiva y de su doble vertiente, que tiene que ver con el tiempo cósmico que nos contiene y trasciende, y también con esa sucesión irreversible, única e irrepetible de instantes que tejen el hilo de cada existencia concreta. En la mitología griega se plasman, por lo tanto, los dos horizontes móviles de tiempo por los que discurre y «se escurre» la vida humana: el tiempo cíclico propio del orden natural, y el tiempo lineal que caracteriza el mundo humano. Además, hay otros mitos que remiten a las posibilidades de alterar y transmutar esa linealidad, que es interrumpida por la fiesta dionisíaca o traza un bucle sobre sí misma con la ayuda de Mnemósine.

Se asume que «el mito ha de ceder a la filosofía la tarea de desplegarlo y de interpretarlo" [Detienne (1985), p. 136], aunque sin perder de vista que hay siempre algo en el mito que se nos escapa, ya que bajo la forma del mito se atisban lo inefable y lo sagrado; expresa aquello que está más allá, o más acá, del discurso racional - y en este sentido se entiende la afirmación de Wittgenstein de que la mitología es un juego del lenguaje-. El mito es un relato simbólico, y el descifrado de los símbolos es un proceso interminable. Pero a pesar de esa complejidad inherente a la tarea de comprender el mito, o precisamente por ello, no sorprende que Heidegger, Gadamer y tantos otros se hayan sentido fascinados por ese campo de infinitas posibilidades que la mitología ofrece para la filosofía, y se hayan adentrado una y otra vez en la "experiencia originaria del mundo» que está inscrita en el laberinto del lenguaje, el concepto y el mito griegos.

\section{Cronos y el tiempo cósmico}

El mito es un relato fundacional y fundante de sentido que intenta explicar «cómo se efectuó algo, cómo comenzó a ser» [Eliade (1981), p. 85]. El mito de Cronos se refiere al inicio del tiempo en términos absolutos, al surgimiento de ese tiempo cósmico que marca, abarca y ordena el mundo natural. Según el relato teogónico de Hesíodo, Cronos es hijo de Gea y Urano, de la tierra y 


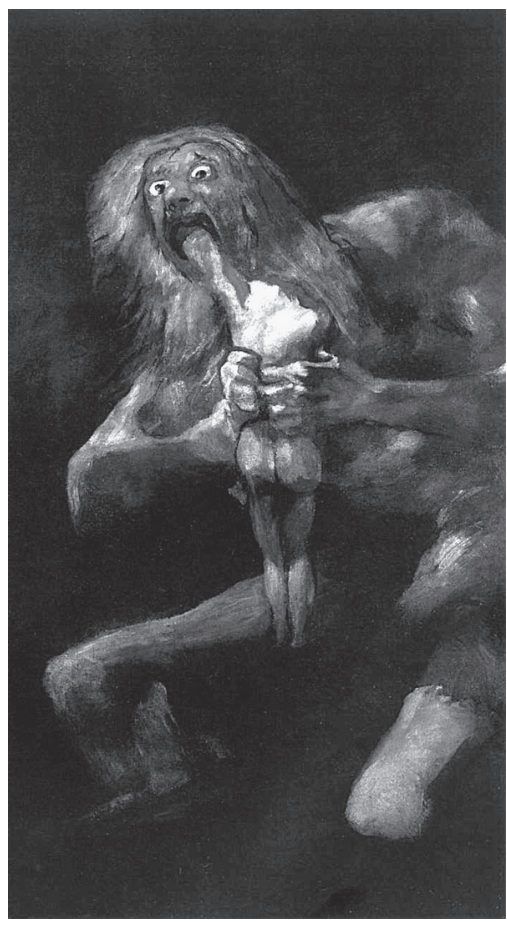

del cielo, y sus hermanos y hermanas (los Titanes y las Titánides) son otras divinidades que representan distintos elementos del orden natural: Océano, Ceo, Crío, Jápeto, Hiperión, Tea, Rea, Temis, Mnemósine, Febe, Tetis, y los monstruos Coto, Briareo y Giges forman parte de ese linaje. García Gual [(1997), p. 110] ha indicado que en la tradición griega posterior a Hesíodo se dio una confusión entre Kronos (hijo de Gea y Urano) y Khronos (el tiempo). Sin embargo, esa fusión de las dos figuras mitológicas primitivas en una única imagen, la de Kronos/ Khronos que devora a sus hijos, proporciona una nueva dimensión simbólica al mito y lo dota de mayor fuerza expresiva ${ }^{3}$.

Por otra parte, y en un intento de aproximación a la mentalidad griega de la época en que los relatos míticos alcanzaron su mayor esplendor, ha de tenerse en cuenta que «la visión de un tejido mítico homogéneo es extraña a la realidad griega de la edad arcaica» [Detienne (1985), p. 66]. Esta actitud flexible, sumada al predominio de la transmisión oral de los relatos míticos durante varios siglos - hasta que Hesíodo y Homero comenzaron a recoger y fijar por escrito esa tradición oral-, contribuyó notablemente a la proliferación de distintas versiones, a veces contradictorias, sobre el mismo mito. "Los mitos son relatos que han ido pasando de generación en generación» [Kirk (1985), p. 291], y además el mito no busca la exactitud ni la precisión, sino que su potencialidad radica en la capacidad evocadora de sus imágenes y en la carga semántica de sus narraciones. Sólo desde esta perspectiva más flexible, profundamente filosófica y enriquecida asimismo por la combinación con otros enfoques psicológicos o literarios, podremos empezar a captar el simbolismo del mito en toda su complejidad y explorar a fondo sus inagotables posibilidades de decir y expresar, de descifrar las claves que ofrece la figura de Cronos para comprender qué es el tiempo y cómo actúa sobre la condición humana.

Cronos es el tiempo universal, de la naturaleza concebida como physis dinámica que crea y destruye con voracidad todo lo engendrado, y que alberga y contiene en su seno a todos los entes. Es significativo además el hecho de que Cronos trague, literalmente, a sus hijos en cuanto éstos nacen, lo que nos da

3 Este mito ha servido de fuente de inspiración para numerosas obras artísticas. Una de las más impactantes es el cuadro de GoyA «Saturno devorando a un hijo», que reproducimos en esta página. 
la medida de nuestra precariedad en tanto que entes caducos: nos disolvemos en el tiempo y nos fundimos con él, éste nos diluye y nos anula, nos empieza a devorar en cuanto nacemos. De aquí se sigue que somos hijos del tiempo y le pertenecemos, formamos parte de él en un sentido radical y en modo alguno podemos huir de esa filiación paterna, pues la vida humana surge en los pliegues de la eternidad. El tiempo nos engendra a la vez que nos destruye, nuestro nacimiento contiene el germen de nuestra propia destrucción porque somos seres finitos —escribió Quevedo: «nacer es empezar a morir»—; esta constancia desgarradora y trágica de nuestra propia finitud es una de las intuiciones más radicales que este mito nos revela. El dominio de Cronos adquiere carácter de ley, instituye una legalidad cósmica inexorable que impone a cada ente una existencia fugaz, transitoria y caduca, pues «parece que el tiempo es algo que envuelve al Cosmos entero" [Zubiri (2008), p. 244]. Esta experiencia de sujeción al tiempo, de percibirse como envuelto y sumergido en él, hace que el ser humano tome conciencia de sí en tanto que «ser lábil», por decirlo con Ricoeur.

Aceptemos la tesis de Sartre de que «el único método posible para estudiar la temporalidad es abordarla como una totalidad que domina sus estructuras secundarias» [(1984), p. 139]. Desde esta perspectiva, ¿acaso no representa Cronos esa temporalidad absoluta que nos contiene y domina, que nos impone su ritmo, que nos sujeta a su voluntad? El dominio del dios Cronos-tiempo «hace del cosmos [...] una esfera única eterna» y apunta a «una aspiración hacia la perennidad y unidad del Todo comparable a la que se expresa, en un plan diferente, en la filosofía de Parménides» [Vernant (1993), p. 109]. Tanto el ser parmenídeo como el Cronos mítico se refieren a la unidad y permanencia. El dios hijo de Urano y Gea, del cielo y de la tierra, representa el tiempo por el que se rige el orden de la naturaleza, esto es, el tiempo como totalidad y horizonte de lo absoluto, de lo que permanece estable más allá de los cambios y encadenamientos de nacimientos y muertes que condicionan y determinan — desde la perspectiva natural— el mundo humano. Más allá de las sucesivas variaciones y vaivenes de la existencia que afectan a los entes concretos, que surgen en el mundo ya con la certeza de que serán devorados y anulados por la temporalidad originaria que los constituye, se atisba - y hacia ahí apunta el mito- que el tiempo como estructura permanece idéntico a sí mismo, fijo e inmutable; es más, esa inmutabilidad del tiempo se manifiesta paradójicamente bajo la forma del dinamismo, porque continuamente está avanzando a velocidad uniforme: «el tiempo no se deja detener» [Heidegger (1996), p. 458]. Cronos es una metáfora de la estabilidad que subyace al cambio y que contiene lo múltiple dentro de sí, representa «el cambio y el devenir de lo uno, que se despliega una y otra vez como múltiple, aunque permanezca en el fondo de las cosas múltiples como unidad» [Fernández Pérez (2010), p. 180]. Todo fluye y todo cambia, pero el tiempo en tanto que estructura tomada en términos absolutos es siempre idéntico en su fluir, porque fluye siempre de igual manera: el cambio es lo único constante y permanente, como nos enseñó Heráclito.

Avanzando un poco más en la interpretación del mito, se puede afirmar que la temporalidad simbolizada por Cronos posibilita también la emergencia de nuevos elementos para la comprensión de lo sagrado. Pues no hay que perder 
de vista que la mitología, más allá de ser una proyección de lo humano y reflejar las pasiones y emociones que nos caracterizan, habla también de los dioses, y conecta de esta manera con otra dimensión cíclica. El tiempo sagrado es «un Tiempo ontológico por excelencia, "parmenídeo": siempre igual a sí mismo, no cambia ni se agota» [Eliade (1981), p. 64]. Se expresa aquí otro paralelismo entre Cronos y el ser de Parménides que hace referencia a la dimensión absoluta de la temporalidad, cuyos límites nos son desconocidos y en cuyos intersticios transcurre nuestra existencia concreta, pues vivimos en ese «entre» el nacimiento y la muerte al que ya se refirió Heidegger. La toma de conciencia de nuestro estar «en el tiempo" y nuestro ser "del tiempo», abordada con perspectiva ontológica, nos permite trascender los límites temporales de la propia inmanencia y conectar con lo absoluto, que se desvela de diferentes formas — entre ellas, bajo la forma de temporalidad primera- en la experiencia de lo sagrado.

Puesto que el mito refleja lo sagrado y relata hechos divinos indemostrables empíricamente, ajenos al orden de lo humano, el modo de aproximarse al mito requiere siempre esa perspectiva oblicua, tangencial e inacabada, inherente a toda toma de contacto con lo numinoso ${ }^{4}$. Esta lectura inscribe al mito en el terreno de la creencia y su significado es descifrado como un «en sí», un núcleo de sentido fundante y dado a priori, de una vez por todas, porque se sitúa en el tiempo de los orígenes y en el origen de los tiempos. En el ámbito de lo sagrado el tiempo se manifiesta como un eterno retorno, es reversible y circular; es «el primer tiempo concebido como órbita de un transcurrir sin avanzar» [Zambrano (2004), p. 50]. Mediante el rito se rememora y conmemora ese tiempo mítico primordial que vuelve a presentarse y (re)presentarse bajo la forma de la celebración. Lo sagrado es paradójico en cuanto a la temporalidad porque «se desvela en la historia y la supera, forma parte de la naturaleza y la desborda» [Pikaza (1999), p. 76]; lo sagrado es lo trascendente que surge en un plano de inmanencia.

En lo sagrado afloran el misterio y lo inefable, se constituye en horizonte trascendente de lo que podemos conocer. $\mathrm{Y}$ es precisamente a partir de ese núcleo — que inaugura el contacto con la infinitud y la alteridad- de donde emerge la posibilidad de un nuevo concepto de temporalidad que recae del lado de lo humano. Desde esta otra perspectiva, el ser humano es aquel que busca trascender su condición temporal y que se rebela, por medio de su inteligencia, contra la finitud que condiciona y alcanza a todos los entes. La mitología griega explica el surgimiento de esa segunda dimensión de temporalidad mediante el relato de cómo el voraz Cronos es destronado por su hijo Zeus:

«Rea, la vida desbordante, logra salvar del hambre devorante de Crono, el Tiempo, a su hijo preferido, Zeus (...) Rea da a Crono una piedra (materia inanimada) para que éste la engulla en lugar de a su hijo Zeus. Crono se deja

4 Sobre las características del encuentro con lo sagrado y sobre el concepto de lo numinoso, cfs. Отто, R. (2009), Ensayos sobre lo numinoso, Madrid, Trotta. Sobre la naturaleza como espacio para el surgimiento de la experiencia de lo sagrado, resultan muy novedosas las tesis recogidas en Gebara, I. (2000), Intuiciones ecofeministas. Ensayo para repensar el conocimiento y la religión, Madrid, Trotta. 
engañar, ya que el tiempo insaciable no puede distinguir entre materia y espíritu (...) Crono es definitivamente destronado; a partir de ese momento se establece el reino del espíritu» [Diel (1985), pp. 111-114].

El espíritu y la inteligencia, representados por Zeus, nacen de la intensa vitalidad de Rea, divinidad que alude a la fecundidad femenina en su vertiente física. Su capacidad procreadora, que permite que continúen naciendo hijos e hijas, logra que la vida fluya, prolifere y se perpetúe a pesar de la ineludible caducidad que el tiempo-Cronos impone a cada ser concreto. Rea es la diosamadre que se alza contra el tiempo que devora a todas las criaturas a las que ella se afana en dar vida. Ella se sirve de la inteligencia-Zeus para ganarle la batalla al tiempo, pues ha llegado a entender que Cronos engulle la materia pero no consigue aniquilar el espíritu. Late aquí el dualismo alma-cuerpo que ya está presente en el orfismo y en toda la tradición mitológica griega anterior, que se prolonga a través de Pitágoras y Platón y que transita por toda la filosofía occidental hasta hoy. El tiempo devora lo material —la muerte implica, por tanto, la destrucción del cuerpo-, pero lo espiritual sobrevive al tiempo - lo que nos remite a la concepción de la inmortalidad del alma- El triunfo de Zeus marca la ruptura con el orden material y terrestre, propio de la naturaleza (y representado por el linaje de Gea, Urano, Rea y Cronos) e instaura el imperio de lo espiritual -lo elevado, el Olimpo: metáfora de lo celeste que se contrapone a lo terrestre y mundano-. Cronos es el tiempo cósmico replegado sobre sí mismo. Al vencerle, Zeus abre un espacio de posibilidad para un nuevo tiempo dinámico, lineal, irreversible y profundamente humano.

\section{El hilo de la vida: las MoIras}

El tiempo mítico fundamenta el tiempo existencial, tiempo de la finitud que condiciona al ser humano al que, «dominado por la fatalidad de la muerte que orienta todo el recorrido, el tiempo en el cual se desenvuelve su existencia le aparece como una potencia de destrucción» [Vernant (1993), p. 110]. Desde la perspectiva de la temporalidad, la existencia humana se caracteriza por dos notas fundamentales: la sujeción al dinamismo y al cambio irreversible (somos seres en devenir), y la precariedad/labilidad originaria que se deriva de nuestra condición de seres finitos (somos seres mortales). Para una lectura en clave existencial es interesante la noción de «recorrido», ese intervalo entre el nacimiento y la muerte que es el tiempo de la vida concreta, por el que nos deslizamos con la incertidumbre de no conocer de cuánto tiempo disponemos y, a la vez, con la certidumbre de saber que en todo caso ese tiempo está limitado por la muerte. En la mitología griega, esta dimensión de la temporalidad humana está simbolizada por las Moiras - también conocidas como Parcas, en la tradición latina-.

Al inicio de su Teogonía, Hesíodo relata que la Noche parió, sin acostarse con nadie, a las Moiras, "vengadoras implacables»: a Cloto, a Láquesis y a Átropo [(1978), p. 80]. En otro pasaje posterior de la misma obra, nuestro autor incurre en una contradicción al afirmar que Zeus se unió a Temis y que fue ésta quien 


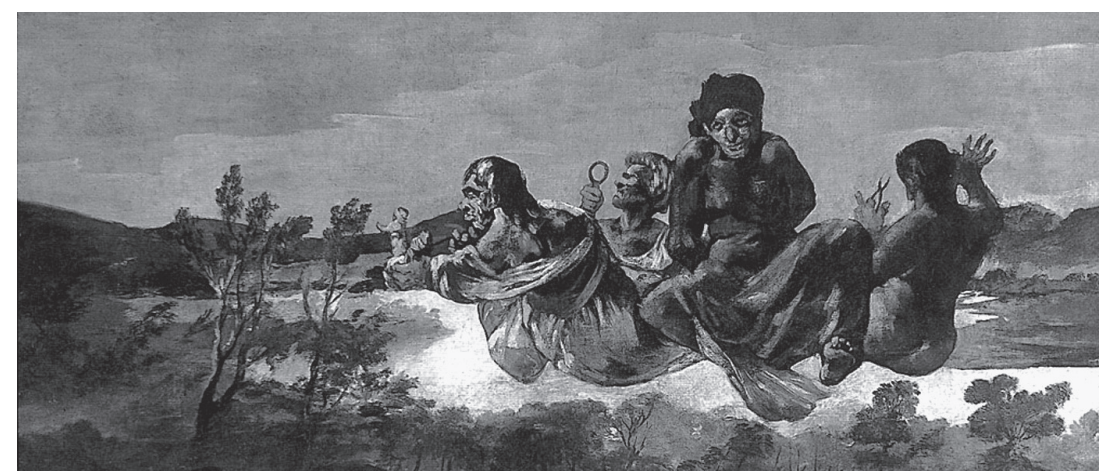

parió a las Moiras [Hesíodo (1978), p. 109]. Estas hermanas son, según el mito, tres viejas hilanderas que se encargan de trazar la urdimbre de la existencia humana. Cada vida en particular es representada por una hebra de lino que sale de la rueca de Cloto, es medida por la vara de Láquesis y se somete al corte de las tijeras de Átropo cuando llega la hora de la muerte. Esta última moira «es la más menuda de tamaño, pero a la vez la más terrible» [Graves (2004), p. 49]. Átropo representa el momento de morir, un breve lapso de tiempo dentro de la totalidad de la vida - y por eso esta moira es, según el mito, «la más menuda de las hermanas»- pero el que más angustia nos produce porque su llegada supone el cierre absoluto, la negación definitiva y radical del fluir de la vida que adviene con la muerte. Este mito nos revela que nuestra vida pende - y depende- de un hilo.

Según la primera versión del mito, las Moiras son hijas de la Noche. Estas hilanderas trabajan en la oscuridad y ocultas a las miradas ajenas, en un espacio completamente inaccesible a los humanos, en ese no-lugar y no-tiempo propios de los mitos. Precisamente esa ubicación en el abismo del no-tiempo —en ese tiempo ontológicamente anterior al tiempo- es lo que posibilita que las Moiras tengan entre sus manos (literalmente) el poder de influir y decidir sobre el tiempo humano, de acotar cada existencia individual. La otra versión del mito sostiene que las Moiras son hijas de Zeus (la inteligencia) y de Temis (la justicia), y desde esa perspectiva encarnan la organización del tiempo vital que Zeus establece para los humanos. En cualquiera de sus dos variantes, la fuerza expresiva y simbólica de este mito resulta indudable ${ }^{5}$.

Omnes feriunt, ultima necat (todas hieren, la última mata); esta cita latina que aparece en la esfera de muchos relojes antiguos y que se refiere a las horas puede aplicarse también a la interpretación del mito de las Moiras: todas sus acciones influyen en los seres humanos, ya que estas hilanderas se ocupan constantemente en entretejer el hilo de cada existencia con los demás hilos, combinando y

5 Aunque la obra de Goya que ilustra esta página es menos conocida que «Saturno devorando a un hijo", el pintor aragonés también retrató a las tres hilanderas mitológicas en "Átropos, Las Parcas o El Destino», una de las «Pinturas negras» con que el artista decoró los muros de su propia casa y que, al igual que su «Saturno», trasluce gran dramatismo. 
trenzando unos con otros, separándolos después para quizás no volver a juntarlos nunca más. Ese quehacer textil simboliza los vuelcos del destino que surgen siempre inesperadamente, y que llevan a Hesíodo a afirmar que las Moiras «conceden a los hombres mortales el ser felices y desgraciados» [(1978), p. 109], ya que los cambios en la urdimbre de la existencia establecen las condiciones, el marco de referencia básico en que cada ser humano busca su camino para ser feliz, siempre con la incertidumbre de lo que el destino le depara: si tendrá fortuna en sus empresas o si será asediado por las desgracias. Por lo tanto, todas las acciones de las Moiras nos hieren, puesto que nos afectan para bien o para mal, y su última acción nos mata: cuando Átropo corta nuestro hilo pone fin a nuestra existencia.

El hombre griego toma así conciencia de su precariedad, "sabe que su vida está ya decidida por el destino, la moira o la aisa, la "suerte" o "porción" que le ha sido asignada» [Eliade (1999), p. 337] y cuyos designios le son desconocidos. Sin embargo, no todo está determinado a priori porque aunque las Moiras tejen el destino de la vida, "no depende de las Moiras la plenitud de la existencia, de ellas depende sólo ese vuelco de las circunstancias que podría llamarse propio del destino» [Jünger (2006), p. 247]. El papel de las Moiras es tejer el telón de fondo en el que se despliega y determina la existencia concreta. Las Moiras marcan la duración del tiempo que nos está asignado y el cupo de venturas y desventuras que nos tocará sufrir a cada uno, pero el modo concreto en que cada ser humano recorre su camino es fruto de la elección personal, de los hábitos que van configurando el carácter o ethos, como ya indicó Aristóteles. «Moira» en griego significa «parte», es la parte que nos toca, la porción de buena y mala suerte que corresponde a cada uno de nosotros en función de una voluntad divina que en ningún caso llegaremos a conocer ${ }^{6}$. Pero se asume que, a pesar de ello, el ser humano puede hacerse partícipe de su destino e intentar ser feliz; para lograrlo, deberá esforzarse al máximo en llevar una vida virtuosa. Las Moiras, hijas de Zeus (la inteligencia y el espíritu), nos recuerdan que el camino de la sabiduría comienza con la aceptación de la finitud y de la radical incertidumbre que afecta a nuestra existencia pues, como afirmó Epicuro, «la conformidad es la mayor de todas las riquezas ${ }^{7}$.

Las Moiras implican una noción de tiempo diferente a la expresada por Cronos; este trío de hilanderas alude a una temporalidad que es continua y dinámica,

6 Según otra interpretación alternativa de este mito, las Moiras representan a la triple diosa Luna, ya que «moira», que significa «parte» o «fase», puede aludir también a las tres fases de la luna: la luna nueva, la luna llena y la luna menguante. Cfs. Graves, R. (2004), Los mitos griegos, Barcelona, Círculo de Lectores. Pero incluso aceptando esta interpretación, esas tres fases lunares simbolizadas por las Moiras funcionan también como metáfora de la juventud, la edad adulta y la vejez, lo cual refuerza la tesis de que este mito alude a la dimensión temporal propia de la existencia humana.

7 Como es sabido a Atenea, diosa griega que representa la sabiduría, se le atribuye también el papel de patrona de las hilanderas, pues se afirma que es ella quien ha enseñado a las mujeres el arte de tejer. Esa conexión simbólica refuerza nuestra lectura del mito de las Moiras en clave de aprendizaje para la vida, de sabiduría ética y práctica que se va adquiriendo y aplicando progresivamente a medida que se avanza en el hilo-transcurso de la existencia. 
lineal e irreversible, que se determina en la concreción de cada existencia y cuya duración ignoramos de antemano, pues la línea del tiempo «es un irrepetible e irreversible ir desde un "antes" hacia un "después"» [Zubiri (2008), p. 231]. Hilar y tejer son metáforas del devenir del tiempo, y la hebra que las Moiras confeccionan para cada ser humano expresa la singularidad del destino individual. El hilo que va tomando forma en la rueca de Cloto alude a ese continuum de la vida, a esa "secuencia de los ahoras ininterrumpida y sin agujeros» [Heidegger (1996), p. 456] que cada ser humano recorre a lo largo de su existencia.

Cada una de las Moiras representa uno de los tres polos de temporalidad de la vida humana: pasado, presente y futuro. George W. Cox ha planteado que esta interpretación del mito no se corresponde con las creencias de los griegos de la época arcaica, sino que forma parte de una exégesis posterior: «el curso de la vida se articula en pasado, presente y futuro, y a partir de ahí se asignó cada uno de esos elementos a un ser concreto. Las tres fatales hermanas son, por tanto, un desarrollo ético» [Cox (1968), p. 61]. Sea como fuere, resulta coherente la interpretación que sostiene que las tres Moiras aluden respectivamente a los tres ejes en los que se engarza el «tiempo de la vida». Cloto, la que hila, es el pasado; esa hebra de nuestra existencia que se ha ido desplegando y entrecruzando con otras hebras, formando el tejido de lo que somos en el momento actual, pues «el pasado es la totalidad siempre creciente del en-sí que somos» [Sartre (1984), p. 147]. Láquesis, la que mide el hilo —o, según otra versión del mito, la que va enroscando el ovillo-, es la metáfora del presente: la praxis nos ha llegado a constituir tal y como somos en el momento actual en tanto que nuestros actos pasados y presentes —es decir, la porción de hilo que llevamos ya recorrida - nos dan la medida de lo que somos, nuestras acciones nos definen y nuestra identidad, que siempre está en proceso de construcción, se relaciona estrechamente con aquello en lo que nos vamos ocupando y enmarañando. El tramo del hilo por el que caminamos, el «ahora» en sentido estricto, nos da la medida puntual y las coordenadas actuales del ser concreto. Y las posibilidades de lo que llegaremos a ser en el futuro vienen dadas por el trozo de hilo que nos resta; esa porción de hilo siempre está por tejer. La única certeza con que el ser humano cuenta con respecto a su propio futuro es la del encuentro con Átropo, que representa el final de la vida y alude a la certidumbre de la propia muerte. Las tijeras de esta moira nos esperan al final del camino, somos «seres-parala-muerte» que cancela y pone fin a toda opción de futuro, de manera que el horizonte de posibilidades que afloran en cada existencia concreta es clausurado definitivamente por la finitud que acaba por alcanzarnos. Si asumimos con Spinoza que «toda determinación es negación», la muerte se determina como la negación más absoluta, al anular toda posibilidad ulterior.

En definitiva, «es el tiempo el que conduce al hombre como sobre una cuerda hacia la muerte» [Jünger (2006), p. 165], y el mito de las Moiras pone de manifiesto que el tiempo humano es "filiforme» y que lo experimentamos primordialmente como devenir lineal, irreversible y finito. Pero las posibilidades que emergen de nuestro horizonte de temporalidad no se agotan ahí, como veremos a continuación. 


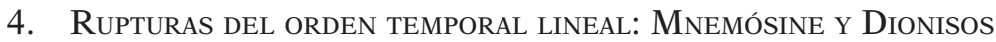

Con Zeus se instaura una temporalidad de carácter lineal representada por las Moiras. Pero el hijo de Cronos representa asimismo el dominio del espíritu que se sobrepone a la naturaleza y consigue vencerla y someterla a su voluntad. Y es precisamente en virtud de ese ámbito del espíritu, del que los humanos son partícipes, que surge la posibilidad de alterar y revertir el curso de la vida. En la mitología griega, la quiebra del tiempo lineal está representada por dos figuras: Mnemósine (la memoria) y Dionisos (la locura y el éxtasis).

\subsection{Mnemósine: el espesor del tiempo}

Mnemósine es una de las Titánides, hija de Gea y Urano y, por tanto, hermana de Cronos, el dios-tiempo. Al igual que su hermano, la figura de Mnemósine alude a una cierta circularidad del tiempo, aunque en un sentido muy diferente al que simboliza Cronos, ya que la temporalidad sobre la que actúa esta diosa no es ya la del orden cósmico y natural replegado sobre sí mismo, sino la de la sucesión consecutiva de instantes en que se incardina la existencia humana. La diosa Memoria posibilita que esa linealidad se altere, permite retroceder puntualmente en el hilo de la vida y trazar un bucle que traiga el pasado al presente.

Al cumplir su función de evocar lo ausente, Mnemósine confiere un nuevo espesor a la temporalidad humana; somos lo que somos en este instante dado, pero a la vez arrastramos con nosotros todo lo que hemos sido porque todo pasado es «originariamente pasado de este presente» [Sartre (1984), p. 143], y es por medio de la memoria que el ser humano logra conectar ambas dimensiones de su propia temporalidad, rescatando y reviviendo el «en sí» de lo que ya ha sido y que no va a volver a ser. Mnemósine hace posible «la transformación de este tiempo de la vida individual - tiempo sufrido, incoherente, irreversible-en un ciclo reconstruido en su totalidad» [Vernant (1993), p. 111]. La memoria hace que el tiempo de la vida se multiplique ${ }^{8}$, supone el triunfo del espíritu sobre la materia y la rebelión del ser humano contra su propio devenir constitutivo. El hilo de la vida se anuda en torno a sí mismo porque el ejercicio de la memoria permite abarcar más elementos que los que están dados de modo inmediato en la mera existencia lineal y sucesiva.

Recordemos, en este sentido, que Mnemósine tenía un manantial que llevaba su nombre, y que al beber de él «resultaba posible recordar ciertas experiencias del pasado e incluso evocar los secretos de quienes ya no estaban entre los vivos» [González Cortés (2007), p. 228]. En las fuentes de la memoria vuelve a brotar, en un ciclo renovado y actualizado, todo lo que ha sido; el pasado es así rescatado del olvido y

8 Es muy significativo que de Zeus (el espíritu) y Mnemósine (la memoria) nazcan las nueve Musas, que representan los distintos caminos de la creatividad, ya que la actividad creadora y artística es un ámbito privilegiado donde se manifiesta el triunfo del espíritu sobre la materia, donde el tiempo se multiplica - al crear nos asomamos a otros mundos, y otros mundos advienen a nuestro mundo- y donde se abre la posibilidad de prolongar la propia vida a través de la fama - que es también, a su vez, otra manifestación de la memoria y del recuerdo-. En esta página, «Mnemosine», de Dante Gabriel Rossetti. 


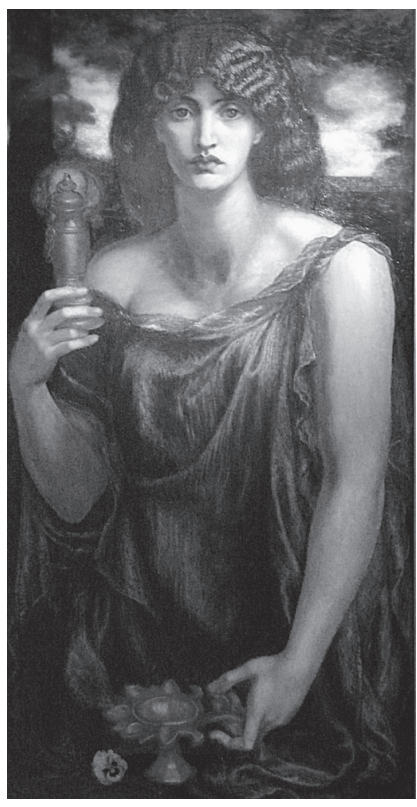

del silencio, y puede hablar de nuevo en el momento actual. En virtud de la memoria el tiempo humano trasciende el límite que el instante le impone; la temporalidad de cada existencia concreta se expande y hace más densa al conectarse el instante actual con la sucesión acumulada de todos los instantes anteriores, que retornan y se hacen presentes a la conciencia bajo la forma del recuerdo.

Asimismo, por medio de la memoria surge un nuevo horizonte de inteligibilidad, una opción alternativa de comprendernos como seres temporales que construyen su identidad en virtud de la historicidad, a medida que van acumulando vivencias y experiencias que permanecen «vivas», presentes en la memoria y que forman parte de la «bio-grafía» dinámica que cada individuo va escribiendo e «inscribiendo» a lo largo de su vivir único e irrepetible. Porque el individuo humano es «el ser cuyo existir consiste en identificarse, en recuperar su identidad a través de todo lo que le acontece» [Levinas (1999), p. 60]; precisamente es la memoria la que posibilita esa recuperación de lo acaecido y, al hacerlo, «aclara, ilumina y colorea, en el recuerdo y el recuento, la realidad» [García Gual (1997), p. 224]. Recordemos que, para Platón, saber es acordarse, "escapar al tiempo de la vida presente, huir lejos de aquí abajo, retornar a la patria divina de nuestra alma» [Vernant (1993), p. 113]. Ese espesor y desdoblamiento de la temporalidad humana posibilitado por la memoria y el recuerdo es condición de posibilidad de todo conocimiento, incluido el filosófico, porque la sabiduría requiere de la anamnesis y «la filosofía siempre es entre-tiempo» [Deleuze y Guattari (1993), p. 161].

\subsection{Dionisos: el tiempo desordenado}

Dionisos, hijo de Zeus y de la ninfa Semele, es el dios que transgrede y altera la sucesión temporal lineal. En la figura de Dionisos se sintetizan lo espiritual — representado por Zeus-y lo terrenal — papel que cumple Semele, que es «humana, demasiado humana»y, por tanto, incapaz de resistir la presencia absoluta y des-velada de lo divino; según el relato mítico, Semele perece abrasada por los rayos de Zeus al contemplar a su dios-amante en su forma divina-. El hijo que Semele alberga en sus entrañas, Dionisos, logra sobrevivir a las llamas porque "fue salvado por la mano poderosa de su padre» [Guerber (2000), p. 126]. El propio Zeus tomó al hijo, todavía sin vida, de las entrañas de su madre, y lo colocó en su cuerpo divino, asumiendo el papel de madre y de gestante ${ }^{9}$. Pasados

9 Éste no es el único pasaje mitológico en que Zeus, literalmente, «da a luz»; recuérdese el mito de Atenea, según el cual Zeus devoró a la titánide Metis cuando ésta estaba 
los meses suficientes nació Dionisos, cuyo nombre significa, etimológicamente, «nacido dos veces». Esta dualidad constitutiva, humana y divina, permite a Dionisos quebrar a la vez los dos planos de temporalidad, el cíclico y el lineal, puesto que la irrupción del dios altera la circularidad del tiempo cósmico, y también por medio de él adviene el caos que enmaraña los hilos que tejen las Moiras.

Cuando aparece el dios del éxtasis místico, del vino y de la embriaguez, «el ser ordenado en el tiempo, tejido con los hilos del tiempo, se torna vacío $y$ hueco, y da comienzo la fiesta de Dioniso, transmutador del tiempo» [Jünger (2006), p. 163]. La celebración dionisíaca da paso a la incertidumbre y lo inesperado, rompe con la monotonía de lo cotidiano y posibilita la emergencia de lo que había permanecido ocul-

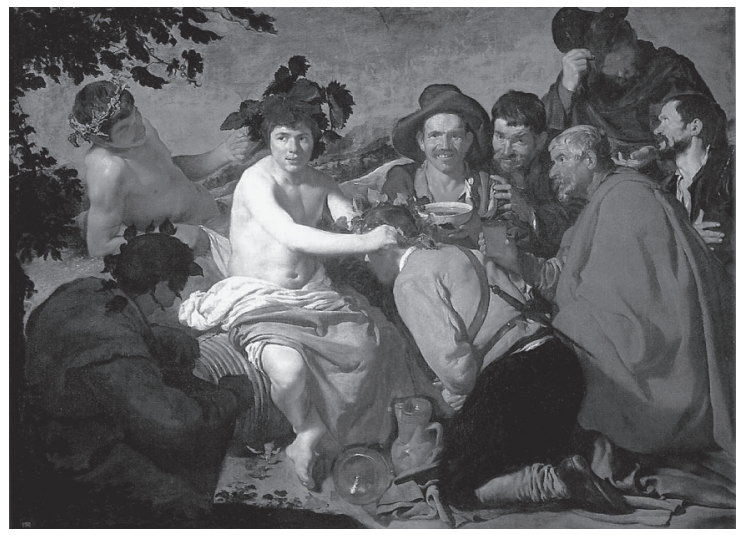
to o reprimido. Esta figura mítica pone de manifiesto la precariedad del orden humano, pues una de las principales consecuencias desencadenadas por la turbulencia que acompaña a Dionisos es que «el mundo que el hombre conoce, el mundo en que se ha asentado de modo seguro, deja de existir» [Otto (1965), p. 95], el orden humano se quiebra y desvanece al entrar en contacto con el caos, cuyo torrente es mucho más poderoso y fluye con más fuerza, arrastrando en su torbellino el fino hilo de la vida humana tomada aisladamente ${ }^{10}$.

Dionisos es el dios que reúne y conecta, que lleva a cabo la síntesis de lo heterogéneo ${ }^{11}$ : «su poder significa olvido de sí mismo y de todo principio de individuación, reconcilia a los hombres entre sí y al ser humano con la naturaleza» [Laiseca (2001), p. 286]. Además, esa multiplicidad y dispersión presentes en lo dionisíaco

embarazada. Llegado el momento del parto la diosa Atenea nació, con ayuda de Hefesto, de la cabeza de su padre Zeus.

10 Es sabido que Nietzsche lleva a cabo una amplia reflexión sobre la relación entre Dionisos y la creatividad artística. Para un estudio pormenorizado sobre esta cuestión, cfs. SÁnchez Meca, D. (2005), Nietzsche. La experiencia dionisíaca del mundo, Madrid, Tecnos. El cuadro de VeLÁzouez «El triunfo de Baco», reproducido en la página anterior, refleja esa transgresión del orden establecido ocasionada por el dios.

11 Dionisos representa la promesa de reunificación de lo disperso porque, según el relato mitológico, cuando era niño fue despedazado por los Titanes y su abuela, Rea (la madre de Zeus y que, como ya se ha dicho, representa la fecundidad femenina), reunió los fragmentos y consiguió hacer revivir a Dionisos y devolverle a su figura primitiva. Es interesante advertir la similitud entre este relato y el mito egipcio de Isis y Osiris, según el cual Isis recoge los restos de su esposo Osiris, esparcidos por el río Nilo, y recompone el cadáver, aunque en el caso egipcio Osiris no vuelve a la vida, como sí acontece con Dionisos. 
permiten que aflore la creatividad, manifestada en el torrente de lo espontáneo y lo desorganizado, inesperado, ya que lo creativo implica siempre un cambio de perspectiva ante las cosas y la aplicación de un punto de vista insólito y alejado de la visión cotidiana del mundo, ordenada y utilitarista.

Dionisos transgrede la sucesión del tiempo lineal, rompe el tejido del tiempo ordenado y tiende al ser humano un nuevo hilo que ya no es el de las Moiras, sino el hilo de Ariadna - la esposa de Dionisos-, que nos permite huir del destino preestablecido y transitar por el laberinto de lo incierto, lo monstruoso, lo desconocido, lo inconsciente, lo aterrador... Por medio de la fiesta y la embriaguez Dionisos, el dios del devenir, nos induce momentáneamente el olvido de la muerte, nos separa de la línea recta que conduce inexorablemente a la finitud y nos insta a adentrarnos en la maraña y el caos de lo que somos, a recorrer el laberinto siguiendo un itinerario que, al contrario que el de la vida ordenada y entretejida por las Moiras, no está fijado de antemano. Y el hilo de Ariadna, profunda conocedora del laberinto y hermana del monstruo que lo habita, nos servirá para que, por mucho que nos internemos en él, podamos siempre encontrar la salida.

El viaje al caos realizado en compañía de Dionisos es siempre un viaje de ida y vuelta, la quiebra del orden temporal lineal provocada por la irrupción de lo dionisíaco no es definitiva sino que supone un punto de fuga, una cierta discontinuidad. En cuanto Dionisos desaparece el tiempo de la vida se reanuda, regresa la consciencia y recordamos que somos «seres-para-la-muerte».

Sin embargo, la existencia se enriquece con la presencia de Dionisos que, al igual que Mnemósine, permite que el tiempo de la vida se expanda y trascienda sus propios límites. Pero ese «espesor» de la temporalidad suscitado por Dionisos es mucho más inquietante que el que surge de la memoria, pues la llegada de este dios implica que «las profundidades de la realidad se han abierto, las formas elementales de todo lo que es creativo, de todo lo que es destructivo, han aflorado, trayendo con ellas infinito terror» [Otto (1965), p. 95]. En él se aglutinan lo divino y lo subterráneo, lo visible y lo invisible, y es por ello que lo dionisíaco conecta con la dimensión de lo sublime, con lo que nos asombra y da miedo con respecto a nosotros mismos ${ }^{12}$. Porque Dionisos nos obliga a asomarnos «al caos de lo que somos», por decirlo con Nietzsche, y porque sólo a través de una voluntad férrea lograremos dominar el miedo que nos produce mirar de frente al fondo del abismo.

12 Recordemos que, para Kant, la experiencia de lo sublime se relaciona con un placer negativo que experimentamos ante aquello que nos atrae y repele a la vez. Lo sublime es superior a lo bello porque golpea la imaginación, eleva al espíritu más allá de sí mismo. Esto es así porque, ante lo ilimitado, nuestra razón postula un infinito que nuestros sentidos no pueden captar. Lo sublime fuerza nuestras capacidades y nos hace ir más allá de nosotros mismos. Cfr. Kant (1973), Prolegómenos a toda metafísica del porvenir. Observaciones sobre el sentimiento de lo bello y lo sublime. Crítica del Juicio, México, Porrúa. La experiencia de lo dionisíaco tiene mucho que ver con esta noción de lo sublime que ya aparece apuntada en Kant, y que remite asimismo al sentido estético de la existencia. En este punto coinciden Kant y Nietzsche. 


\section{CONSIDERACIONES FINALES}

A lo largo de este escrito se han revisado los dos modos principales de pensar la temporalidad, y se ha podido constatar que ambas nociones de tiempo, la circular y la lineal, que han permeado todas las reflexiones sobre el tema a lo largo de la historia occidental, están ya presentes en la mitología griega. Esta presencia tan intensa y rica en matices que aquí hemos intentado desgranar da muestra de la flexibilidad del pensamiento mitológico previo a la filosofía, y permite además tender puentes y señalar nexos conceptuales entre las nociones de temporalidad manifiestas en el pensamiento griego arcaico y en las reflexiones de los primeros textos de la filosofía, que recogen las ideas de Parménides, Heráclito o Platón.

En primer lugar, el tiempo del mito es un tiempo sagrado en el que, recursivamente, emerge lo sagrado como experiencia fundante de sentido. El mito de Cronos alude claramente a ese tiempo originario e intenta explicar cómo todos y cada uno de los entes temporales que han existido y existirán están contenidos en él. El tiempo del mito se revive a través del rito que, repetido, refuerza esa percepción del carácter circular del tiempo de la naturaleza, del tiempo cósmico del que surgimos.

La victoria de Zeus sobre Cronos y el surgimiento de las Moiras representan el advenimiento del tiempo humano, el tiempo de la vida que se va hilando y entretejiendo con otras vidas para conformar un entramado de interacciones, un contexto vital. Desde esta perspectiva, cada vida concreta puede ser interpretada en clave ecosistémica; cada hebra interactúa con todas las demás hebras para formar un tapiz más complejo: el tapiz del mundo humano del que todos y cada uno somos partícipes. Ese tapiz tiene una historicidad de límites difusos; es imposible datar su fecha concreta de inicio, y tampoco tiene fecha prevista para su finalización ya que, al igual que el sudario de Penélope, la esposa de Odiseo, su trama está continuamente siendo tejida, destejida y vuelta a tejer.

Además de entrelazarse con otros hilos e ir variando en función de los giros que describe, el hilo de cada vida singular se engrosa o estrecha por momentos a partir de distintas vivencias que hacen que la percepción subjetiva del tiempo se intensifique o se haga más leve. Los juegos de la memoria y los juegos del olvido, la suma de monotonía y de notas discordantes y, en definitiva, la irrupción de Mnemósine y de Dionisos, posibilitan que la vida humana no sea simplemente un movimiento uniforme y rectilíneo, sino que pueda también replegarse sobre sí misma, volver hacia el pasado, desdoblar el tiempo o incluso interrumpir momentáneamente su cauce... así, la vida se despliega como una síntesis de «ahoras» heterogéneos por los que la conciencia se desliza de modo continuo. El tiempo vivido es una colección siempre en aumento de momentos importantes $\mathrm{u}$ olvidados, de instantes que son percibidos con gran intensidad y recordados una y otra vez o que, por el contrario, resultan anodinos e irrelevantes y se diluyen en el cauce de la conciencia apenas han transcurrido. Las Moiras tejen el hilo, sí, pero es el ser humano, cada ser humano concreto, el que da sentido a la trama; el que construye el sentido de su existencia a lo largo del tiempo. 


\section{REFERENCIAS BIBLIOGRÁFICAS}

Bermejo, J. C. y Díez, F. (2002), Lecturas del mito griego, Madrid, Akal.

Cox, G. W. (1968), An introduction to the science of comparative mythology and folklore, Detroit, Singing Tree Press.

Deleuze, G. y Guattari, F. (1993), ¿Qué es filosofía?. Barcelona, Anagrama.

Detienne, M. (1985), La invención de la mitología, Barcelona, Península.

Diel, P. (1985), El simbolismo en la mitología griega, Barcelona, Labor.

Downing, C. (1998), La diosa. Imágenes mitológicas de lo femenino, Barcelona, Kairós.

Eliade, M. (1981), Lo sagrado y lo profano, Barcelona, Labor.

- (1999), Historia de las creencias y las ideas religiosas. Vol. I. De la Edad de Piedra a los Misterios de Eleusis, Barcelona, Paidós.

Fernández Pérez, G. (2010), Heráclito. Naturaleza y complejidad, Madrid y Sevilla, Plaza y Valdés y Thémata.

Gadamer, H.-G. (1997), Mito y razón, Barcelona, Paidós.

García Gual, C. (1997), Diccionario de mitos, Barcelona, Planeta.

GonzÁlez CoRTés, M. T. (2007), Los viajes de Jano. Historias del cuerpo, Barcelona, Icaria.

Graves, R. (2004), Los mitos griegos, Barcelona, Círculo de Lectores.

Guerber, H. A. (2000), The Myths of Greece and Rome, Ware, Wordsworth.

Heidegger, M. (1996), El ser y el tiempo, Madrid, Fondo de Cultura Económica.

Hesíodo (1978), Obras y fragmentos. Teogonía. Trabajos y días. Escudo. Fragmentos. Certamen, Madrid, Gredos.

JüngER, F. G. (2006), Mitos griegos, Barcelona, Herder.

KIRK, G. S. (1985), El mito. Su significado y funciones en la Antigüedad y otras culturas, Barcelona, Paidós.

- (2002), La naturaleza de los mitos griegos, Barcelona, Paidós.

LAiseca, L. (2001), El nihilismo europeo, Buenos Aires, Biblos.

Levinas, E. (1999), Totalidad e infinito. Ensayos sobre la exterioridad, Salamanca, Sígueme. Отто, W. (1965), Dyonisus: Myth and Cult, Bloomington, Indiana University Press.

Pikaza, X. (1999), El fenómeno religioso, Madrid, Trotta.

Ricoeur, P. (1982), Finitud y culpabilidad, Madrid, Taurus.

SARTRE, J.-P. (1984), El ser y la nada, Madrid, Alianza.

Vernant, J.-P. (1993), Mito y pensamiento en la Grecia Antigua, Barcelona, Ariel.

Zambrano, M. (2004), Los sueños y el tiempo, Madrid, Siruela.

ZubIRI, X. (2008), Espacio, tiempo, materia, Madrid, Alianza Editorial.

Departamento de Ciencias Humanas-Área de Filosofía Moral

Universidad de La Rioja

Olaya Fernández Guerrero

olayafg@yahoo.es

[Artículo aprobado para publicación en diciembre de 2012] 